\title{
Evaluation of Cytogenetic Alterations of Toxic Gas Exposed Population of Bhopal Having Chronic Kidney Disease
}

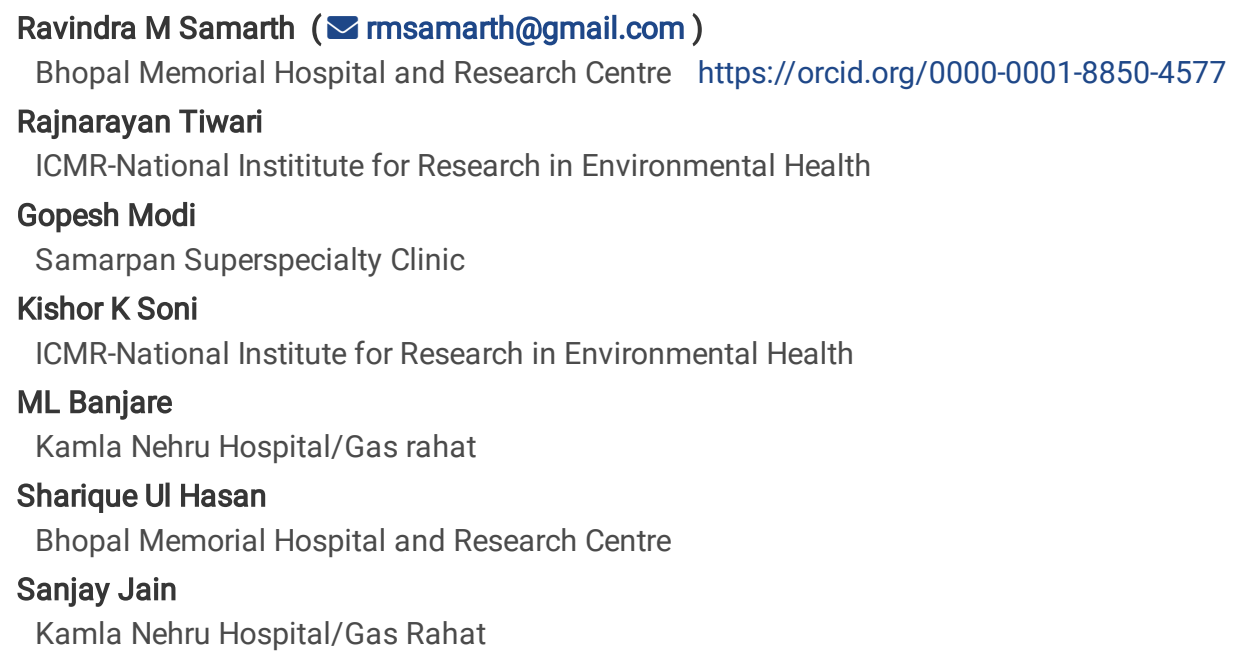

Keywords: Chronic kidney disease, chromosomal aberration analysis, micronuclei assay, genetic damage

Posted Date: December 20th, 2021

DOI: https://doi.org/10.21203/rs.3.rs-1041955/v2

License: () (i) This work is licensed under a Creative Commons Attribution 4.0 International License. Read Full License 


\section{Abstract}

The industrial disaster of Bhopal in 1984 resulted in widespread morbidity and mortality in the vicinity of the industry and required long-term surveillance for chronic health effects in those affected by the leakage of gas. Although few cytogenetic studies were undertaken to assess genetic damage in survivors of the disaster, no studies are available on cytogenetic damage of toxic gas-exposed populations having chronic kidney disease (CKD). Thus, the present study aimed to evaluate cytogenetic alterations in chronic kidney disease patients who were exposed to leaked gas and to compare it with those who were not exposed to the leaked gas. The cytogenetic alterations were evaluated through chromosomal aberration analysis and micronuclei assay. The study included 608 study participants divided into four groups based on the history of exposure to the leaked gas and the presence or absence of CKD. The results of the study showed no statistically significant difference in cytogenetic damage between gas-exposed and non-exposed patients of CKD. However, significantly higher cytogenetic damage was observed among gas-exposed participants having CKD as compared to gas-exposed participants free from CKD. Thus, to conclude though the cytogenetic alterations were observed in an exposed group it cannot be solely attributed to the gas exposure and the role of other confounders must also be studied.

\section{Introduction}

Industrial disasters have widespread implications in terms of population affected, the magnitude of morbidity, and the number of bodily systems affected. The story of the 1984 Bhopal Gas disaster has been no different. It has affected all-important body systems directly or indirectly probably kidneys also. As a result, the need for continuous observations for assessment of long-term effects in toxic gas exposed individuals has been advocated [1-3].

In recent years there has been a rise in chronic kidney diseases and it has been estimated that by 2040 it will be the 5 th most common cause of death globally. Therefore, it is essential to enhance the awareness of the importance of preventive measures among the population, professionals, and policymakers [4]. In 2020, there were 697.5 million cases of chronic kidney disease worldwide having a prevalence rate of 9.1\% [5]. The global all-age prevalence has increased to 29.3\% during 1990-2017 with stable age-standardized prevalence, and 1.2 million deaths occurred due to CKD in 2017. The CKD is commonly connected with diabetes, hypertension, obesity, hyperlipidemia, and non-alcoholic fatty liver disease [6-7]. These factors not only act as initiators but also promoters for kidney diseases [8]. However, the Indian CKD Registry published in 2012 emphasized on etiology and demographics of the country [9]. Though the elementary diagnostic parameters commonly used to detect CKD include measurement of serum creatinine, GFR, and urinary albumin levels [10], an exploration of the role of epigenetic mechanisms for their translational efficacy as a novel therapy for CKD was advocated [11].

The genetic damage in CKD patients could be attributed to various factors such as increased uraemic toxins and endogenous genotoxic products including oxidative stress intermediaries that result in genomic instability [12]. Genetic makeup is attributed to the damaged DNA repair mechanisms. Attention is being paid to oxidative DNA damage because of its complex genetic effects contributing to early aging, neurodegenerative disorders, diabetes, atherosclerosis, mutagenesis, and carcinogenesis [13]. Generally, in CKD patients, the genomic damage has been measured applying cytogenetic techniques through evaluation of sister chromatid exchange (SCE) rates and micronuclei (MN) frequency in peripheral blood lymphocytes [14-15]. Recently, it has summarized the most important human studies evaluating genomic biomarkers for CKD [16]. The possibility of the association of CKD with genetic variation of chromosome $\mathrm{Y}$ has also been studied [17].

Post-disaster, the Indian Council of Medical Research made attempts to assess the severe effects of toxic gas on the exposed population [1819]. However, low birth weight, genetic/developmental/growth disorders, and respiratory ailments were thrust areas of research. Few cytogenetic studies were also undertaken to assess genetic damage in the gas-exposed population. However, no studies are available on cytogenetic damage of toxic gas exposed population having CKD. Therefore, this study was undertaken to evaluate cytogenetic damage through chromosomal aberration analysis (CA) and MN assay among gas exposed survivors in the presence or absence of chronic kidney disease

\section{Materials And Methods}

This cross-sectional multi-group study was undertaken at Bhopal. The study was approved by the Institutional ethics committee (IEC) of ICMRNational Institute for Research in Environmental Health Bhopal and written informed consent was taken from each participant before initiating the study. Based upon the frequency of SCE and MN among control and CKD patients as available from literature, at 0.05 level of significance and $80 \%$ power the sample size was calculated to be 175 subjects in each of the four groups. These four groups included those exposed to gas and having CKD (Group I); those not exposed to gas but having CKD (Group II); those exposed to gas and free from CKD (Group III) and those not exposed to gas and also free from CKD (Group IV). Excluding the pregnant/lactating females, those with congenital anomalies and malignancies, all other diagnosed cases of CKD including those in hypertensive and diabetic patients aged 30 years or more and reporting at government and/or private tertiary care centers during the study period were included. 
All the participants possessing the ICMR registration card issued for long-term surveillance studies were considered as gas exposed participants while those not possessing that card were considered as non-exposed. Thus, a total of 608 participants were recruited which comprises 167 in Group I, 116 in Group II, 162 in Group III, and 163 in Group IV. However, due to the failure of culture in 26 participants, the final analysis included 582 participants which included 160 in Group I, 106 in Group II, and 158 each in Group III and IV.

The standard methods were adopted for the preparation of chromosomal aberration analysis and micronucleus assay [20-23]. For the cytogenetic study, $3 \mathrm{ml}$ peripheral blood sample was collected in sterile sodium heparin vacutainer by venepuncture. Peripheral blood (0.5 ml) was added to $4 \mathrm{ml}$ RPMI 1640 medium supplemented with $20 \%$ fetal bovine serum and phytohaemagglutinin (PHA) and maintained at $37^{\circ} \mathrm{C}$ for 72 hrs. For each individual, the cultures were set up in duplicates and two separate sets. One set was used for chromosomal analysis while another set was used for MN assay. The values for cytogenetic parameters such as frequency of micronuclei (MN), nuclear division index (NDI), mitotic index (MI), frequency of dicentrics, rings, chromatid breaks, and fragments were recorded.

The statistical analysis was done using the statistical software SPSS 25.0. The frequencies of cytogenetic parameters were expressed as mean and standard error. For analysis, the study variables were age (arbitrarily dichotomized into $<45$ and $\geq 45$ ), gender, history of exposure, and presence or absence of CKD while the outcome variables were the cytogenetic parameters. The mean of cytogenetic parameters according to study variables was compared using the Student's t-test. The group-wise comparison of cytogenetic parameters was done by one-way ANOVA followed by post-hoc LSD. The significance levels were set at $p<0.05$.

\section{Results}

The present study included 365 males (168 with CKD and 197 without CKD) and 217 females (98 with CKD and 119 without CKD) participants. Thus, the ratio of M: F for CKD was 63:37. Table 1 depicts the mean values for cytogenetic parameters according to study variables. It can be observed that those aged $\geq 45$ years were having a significantly higher mean of micronuclei, chromatid breaks, and fragments while significantly lower mean mitotic index than those aged $<45$ years. According to gender females had higher mean mitotic index, chromatid breaks, and fragments as compared to males. Further, those exposed to toxic gas and those having CKD had higher mean values of micronuclei, $\mathrm{NDI}$, dicentrics, rings, chromatid breaks, and fragments as compared to those not exposed to toxic gas and those free from CKD respectively.

Table 1

Distribution of cytogenetic parameters according to the study variables

\begin{tabular}{|c|c|c|c|c|c|c|c|c|}
\hline Characteristics & $\mathbf{N}$ & MN & NDI & MI & Dicentrics & Rings & $\begin{array}{l}\text { Chromatid } \\
\text { breaks }\end{array}$ & Fragments \\
\hline Age $<45$ years & 221 & $3.28 \pm 0.23$ & $2.27 \pm 0.08$ & $5.28 \pm 0.09$ & $0.09 \pm 0.02$ & $0.04 \pm 0.01$ & $0.95 \pm 0.09$ & $1.50 \pm 0.12$ \\
\hline$\geq 45$ years & 361 & $4.15 \pm 0.19$ & $2.31 \pm 0.06$ & $4.99 \pm 0.07$ & $0.13 \pm 0.02$ & $0.04 \pm 0.01$ & $1.43 \pm 0.09$ & $2.12 \pm 0.09$ \\
\hline F; p-value & & $8.28 ; 0.004^{\star}$ & $0.18 ; 0.669$ & $5.81 ; 0.016^{\star}$ & $1.94 ; 0.164$ & $0.22 ; 0.639$ & $12.69 ; 0.000 *$ & $15.51 ; 0.000 *$ \\
\hline Gender Male & 365 & $3.68 \pm 0.18$ & $2.29 \pm 0.06$ & $4.99 \pm 0.08$ & $0.10 \pm 0.02$ & $0.04 \pm 0.01$ & $1.12 \pm 0.08$ & $1.77 \pm 0.09$ \\
\hline Female & 217 & $4.05 \pm 0.26$ & $2.31 \pm 0.07$ & $5.29 \pm 0.09$ & $0.13 \pm 0.02$ & $0.14 \pm 0.02$ & $1.47 \pm 0.12$ & $2.08 \pm 0.14$ \\
\hline F; p-value & & $1.44 ; 0.231$ & $0.07 ; 0.792$ & $6.60 ; 0.01^{*}$ & $1.80 ; 0.18$ & $0.002 ; 0.961$ & $6.79 ; 0.009 *$ & $3.96 ; 0.047$ * \\
\hline $\begin{array}{l}\text { Exposure } \\
\text { Absent }\end{array}$ & 264 & $3.18 \pm 0.22$ & $2.12 \pm 0.07$ & $5.33 \pm 0.09$ & $0.10 \pm 0.02$ & $\begin{array}{l}0.02 \pm \\
0.008\end{array}$ & $0.93 \pm 0.09$ & $1.49 \pm 0.10$ \\
\hline Present & 318 & $4.35 \pm 0.19$ & $2.44 \pm 0.06$ & $4.92 \pm 0.08$ & $0.13 \pm 0.02$ & $0.06 \pm 0.01$ & $1.52 \pm 0.09$ & $2.21 \pm 0.19$ \\
\hline F; p-value & & $15.87 ; 0.000 *$ & $11.28 ; 0.001 *$ & $12.54 ; 0.000$ * & $0.73 ; 0.394$ & $6.19 ; 0.013^{\star}$ & $20.22 ; 0.000 *$ & $22.38 ; 0.000 *$ \\
\hline CKD bsent & 316 & $1.40 \pm 0.06$ & $1.91 \pm 0.06$ & $5.34 \pm 0.08$ & $0.05 \pm 0.01$ & $\begin{array}{l}0.02 \pm \\
0.008\end{array}$ & $0.37 \pm 0.03$ & $0.71 \pm 0.04$ \\
\hline Present & 266 & $6.69 \pm 0.21$ & $2.75 \pm 0.07$ & $4.82 \pm 0.08$ & $0.19 \pm 0.03$ & $0.06 \pm 0.02$ & $2.30 \pm 0.11$ & $3.28 \pm 0.11$ \\
\hline F; p-value & & $699.7 ; 0.000 *$ & $90.3 ; 0.000 *$ & $21.49 ; 0.000$ * & $24.59 ; 0.000$ * & $6.53 ; 0.011^{*}$ & $336.74 .22 ; 0.000 *$ & $524.26 ; 0.000 *$ \\
\hline
\end{tabular}

Table 2 shows the distribution of cytogenetic parameters according to different groups. The one-way ANOVA showed that there was a declining trend in the mean values for all cytogenetic parameters according to the group. The post-hoc test revealed that there was a significant increase in frequencies of micronuclei (MN) and NDI values in Group I, Group II, and Group III as compared to Group IV ( $p=0.000)$. When the non-exposed CKD group (Group II) and exposed CKD group (Group I) were compared, there was no significant difference in values of MN frequency ( $\mathrm{p}=0.229)$ and NDI $(p=0.576)$. However, the values of MN frequencies and NDI were significantly higher in exposed CKD groups (Group-I) as compared to 
exposed non-CKD (Group III). Further significant changes in values of mitotic index (MI) in Group I, Group II, and Group III was observed as compared to Group IV(p=0.000).

Table 2

Group-wise comparison of cytogenetic parameters

\begin{tabular}{|c|c|c|c|c|c|c|c|c|}
\hline Groups & $\mathbf{N}$ & MN & NDI & MI & Dicentrics & Rings & $\begin{array}{l}\text { Chromatid } \\
\text { breaks }\end{array}$ & Fragments \\
\hline Group 1 & 160 & $6.83 \pm 0.26^{\star \#}$ & $2.78 \pm 0.08^{\star \#}$ & $4.87 \pm 0.11^{\#}$ & $0.18 \pm 0.03^{\star \#}$ & $0.08 \pm 0.02^{\star \#}$ & $2.59 \pm 0.13^{\% \star \#}$ & $\begin{array}{l}3.58 \pm \\
0.14^{\%^{\star} \#}\end{array}$ \\
\hline Group 2 & 106 & $6.47 \pm 0.34^{\star \#}$ & $2.71 \pm 0.11^{\star \#}$ & $4.74 \pm 0.13^{\#}$ & $0.20 \pm 0.04^{\star \#}$ & $0.04 \pm 0.02$ & $1.87 \pm 0.17^{\circledR * \#}$ & $\begin{array}{l}2.83 \pm \\
0.18^{@ * \#}\end{array}$ \\
\hline Group 3 & 158 & $\begin{array}{l}1.83 \pm \\
0.08 @ \% \#\end{array}$ & $\begin{array}{l}2.09 \pm \\
0.08 @ \% \#\end{array}$ & $4.97 \pm 0.10^{\#}$ & $\begin{array}{l}0.07 \pm \\
0.02 @ \%\end{array}$ & $0.04 \pm 0.02^{@}$ & $0.43 \pm 0.05 @ \%$ & $\begin{array}{l}0.83 \pm \\
0.06 @ \%\end{array}$ \\
\hline Group 4 & 158 & $\begin{array}{l}0.97 \pm \\
0.07 @ \%\end{array}$ & $\begin{array}{l}1.73 \pm \\
0.09 @ \%\end{array}$ & $\begin{array}{l}5.72 \pm \\
0.11^{@ \% *}\end{array}$ & $\begin{array}{l}0.04 \pm \\
0.02 @ \%\end{array}$ & $\begin{array}{l}0.01 \pm \\
0.006 @\end{array}$ & $0.30 \pm 0.05^{@ \%}$ & $\begin{array}{l}0.59 \pm \\
0.06 @ \%\end{array}$ \\
\hline $\begin{array}{l}\mathrm{F} ; \mathrm{p}- \\
\text { value }\end{array}$ & & $241.11 ; 0.000$ & $33.7 ; 0.000$ & $15.90 ; 0.000$ & $8.48 ; 0.000$ & $3.91 ; 0.009$ & $123.67 ; 0.000$ & $188.53 ; 0.000$ \\
\hline \multicolumn{9}{|c|}{ @Significant when compared with Group 1 *Significant when compared with Group 3} \\
\hline
\end{tabular}

The frequency of dicentrics also showed a statistically significant difference $(\mathrm{p}=0.000)$ in Group I, Group II as compared to Group IV while no significant difference was observed between Group III and Group IV ( $p=0.394)$. Further analysis showed a highly significant $(p=0.000)$ difference for values of dicentric frequencies in males of Group I and Group II as compared to Group IV. Though, a significant ( $<<0.05$ ) difference was noticed for values of dicentric frequencies in females of Group I and Group II as compared to Group IV, no such significant difference was observed in Group III as compared to Group IV. The Group I participants had a significantly higher mean number of rings as compared to Group III ( $p=0.049)$ and Group IV ( $p=0.001)$ participants. However, the difference was non-significant when compared with Group II ( $p=0.077)$.

Similarly, though the frequencies of chromatid breaks and fragments showed a significant increase in Group I and Group II as compared to Group IV $(p=0.000)$, no such significant difference was observed in Group III as compared to Group IV for the frequencies of chromatid breaks $(p=0.367)$ and fragments $(p=0.116)$.

No significant difference was observed for values of MI, dicentrics, and rings of Group I (Exposed-CKD) as compared to Group II (Non-exposedCKD). However, a highly significant increase was observed for frequencies of chromatid breaks and fragments in Group I as compared to Group II $(p=0.000)$. In the case of comparison between Group I and Group III, no significant difference was noticed for MI but a significant increase was observed for frequencies of dicentrics $(p=0.002)$, rings $(P=0.049)$ chromatid breaks $(p=0.000)$, and fragments $(p=0.000)$.

\section{Discussion}

In the present study, no significant difference was observed in cytogenetic endpoints between exposed CKD and non-exposed CKD patients. A significant difference was noted between exposed CKD and exposed non-CKD patients in terms of MN frequency, NDI, chromatid breaks, and fragments. Several studies have shown that chronic kidney failure patients had higher levels of genetic damage [24-27]. In the present study, the cytogenetic alterations observed may not be solely assigned to toxic gas exposure because the effects of confounding variables too contribute to the genetic damage. Overproduction of reactive oxygen species in CKD patients may lead to DNA damage. The imbalance between antioxidant defense mechanisms and excess production of oxidants is augmented in CKD [28]. The conditions of hypertension and dyslipidemia are also being augmented by CKD that in turn encourages the progression of kidney failure [29]. It has been noticed that epigenetic alterations are linked with inflammation and cardiovascular ailment in CKD patients [30]. The increased angiotensin II levels found in CKD patients that enhance premature aging might directly impact the pathophysiology and therapeutics in CKD [27]. Several enhanced pro-oxidant actions also lead to CKD and these are age, hypertension, inflammation, and incompatibility of dialysis membranes [31]. It has been noted that a variety of factors prejudice the formation of MN in cells of CKD like age, sex, genetic makeup, physical and chemical agents as well as the habitual practice of chewing and/or smoking tobacco and drinking alcohol [32]. The conventional and molecular cytogenetic findings are too important in the management of CKD possibly for reducing genomic instability [33].

It was observed that the advanced CKD patients showed more DNA damage, and such damage was increased after hemodialysis in Type 2 Diabetes mellitus [34-35]. Exposure to metals in CKD patients can lead to reductions in kidney functions [36]. Thus, the confounders can be a lifestyle, living environment, nutritional factors, drinking water, and occupational exposure to other toxicants [37]. It was opined that alterations 
in NDI value are directly related to the proliferative ability of the cell [38]. The urinary cell-free mitochondrial DNA and nuclear DNA could be employed as prognostic biomarkers for kidney outcome in CKD [39]. Recently, observation was noted that CKD patients had increased levels of circulating cell-free DNA as well as different types of DNA damage [40].

The exposed non-CKD Group when compared to the non-exposed non-CKD Group, showed significant cytogenetic damage in terms of MN frequency and NDI. In Chromosomal assay, MI showed a significant decrease but no significant difference was observed for dicentrics, rings, chromatid breaks, and fragments. A few reports are available on the cytogenetic alterations of the individuals exposed to toxic gas [41-43]. The higher chromosomal damage was reported in toxic gas-exposed women [44]. The types of abnormalities recorded were chromosome breaks, gaps, dicentrics, rings, and triradial and quadriradial configurations. It was observed that the mean percentage of acrocentric associations in the toxic gas exposed population was significantly higher as compared to the control [45]. The persistence of genomic instability in terms of higher chromosomal aberrations and atypical lymphocytes was also noticed in the toxic gas-exposed population of Bhopal [46-47]. A pilot follow-up study after 30 years of the tragedy reported stable or clonal rearrangements even after 30 years in the increased SCE and decreased replicative index seen immediately after toxic gas exposure. It also demonstrated a correlation between age, exposure status, and cytogenetic alterations in toxic gas-exposed individuals [48].

The study has several limitations. Firstly the toxic gas exposure was subjectively done as there were not sufficient methods for exposure assessment 37 years back when the tragedy struck. It was crude based on the number of mortality that occurred at the time of the accident. Secondly, as the cases were recruited through the hospital, the information on many confounders of such cytogenetic changes was limited and thus limits the generalization of the findings of the study. Thirdly sequential measurement of cytogenetic parameters along with environmental measurement of various toxic pollutants would have given a better causal-effect relationship of toxic gas exposure with cytogenetic changes.

Thus, to conclude, though the cytogenetic changes are reported similar to earlier studies, it cannot be solely attributed to the exposure to toxic gas as many confounding factors may also contribute to genetic damage but such studies are significant for assessing the risk [49]. Further, because of the complex interactions between environment, disease susceptibility, and genetic susceptibility, the exploration of epigenetic mechanisms to meet the challenges of CKD through novel ideas of molecular mechanisms is warranted.

\section{Declarations}

\section{Authors Contribution}

Ravindra M Samarth has conceptualized, analyzed the data, and participated in writing the manuscript, and is the corresponding author. Gopesh Modi, Kishor K Soni, Shariq UI Hasan, M.L. Banjare, and Sanjay Jain contributed to sample collection, data generation and participated in writing the article. Ravindra M Samarth and RR Tiwari have revised, reviewed, and approved the final draft.

\section{Grant/Funding}

Indian Council of Medical Research (Department of Health Research, MoHFW, Government of India) financial support through Project Grant ICMR No. 65 / 3/ RMS/ NIREH/ 2015-NCD-II) to Ravindra M Samarth.

\section{Conflict of Interest: None}

The authors are thankful to donors for giving blood samples for the study. The financial support from the Indian Council of Medical Research (Department of Health Research, MoHFW, Government of India) financial support through Project Grant ICMR No. 65 / 3/ RMS/ NIREH/ 2015NCD-II) to RMS is thankfully acknowledged. The authors are thankful to Director ICMR-BMHRC, Bhopal, and Director ICMR-NIREH, Bhopal for providing required administrative support and laboratory facilities for the smooth conduct of the study. Technical assistance provided by Pranjali Borkar (SPRF), Abhimanyu Keshawani / Vaishali Yadav (JPRF), and lab technicians Mr. Saikant Wahane, Rishi Badal, and Manish Babu Yadav, is also thankfully acknowledged.

\section{Conflict of Interest}

Authors declare that no financial or non-financial interests are directly or indirectly related to the work submitted for publication.

\section{References}

1. Mishra PK, Samarth RM, Pathak N et al (2009) Bhopal Gas Tragedy: Clinical and Experimental Findings, view after 25 years. Int J Occup Med Environ Health 22:193-202

2. Shrivastava R (2011) Bhopal gas disaster: Review on health effects of methyl isocyanate. Research Journal of Environmental Science $5(2): 150-156$ 
3. Samarth RM, Gandhi P, Maudar KK (2013) Retrospective review of cytogenetic studies on Methyl Isocyanate with special reference to Bhopal Gas Tragedy: Is the next generation also at risk? Int J Occup Med Environ Health 26(3):324-336

4. Li PK, Garcia-Garcia G, Lui SF et al (2020) World Kidney Day Steering Committee; Members of the World Kidney Day Steering Committee. Kidney Health for Everyone Everywhere - From prevention to detection and equitable access to care. Nefrologia 40(2):133-141

5. Bikbov B, Purcell CA, Levey AS et al (2020) Global, regional, and national burden of chronic kidney disease, 1990-2017: a systematic analysis for the Global Burden of Disease Study 2017. The Lancet 395(10225):709-733

6. Targher G, Chonchol M, Zoppini G et al (2011) Risk of chronic kidney disease in patients with non-alcoholic fatty liver disease: is there a link? J Hepatol 54(5):1020-1029

7. Targher G, Byrne CD (2017) Non-alcoholic fatty liver disease: an emerging driving force in chronic kidney disease. Nat Rev Nephrol 13(5):297-310

8. Levey AS, Coresh J (2012) Chronic kidney disease. The Lancet 379(9811):165-180

9. Rajapurkar MM, John GT, Kirpalani AL et al (2012) What do we know about chronic kidney disease in India: first report of the. Indian CKD registry BMC Nephrology 13:10

10. Jha V, Garcia-Garcia G, Iseki K et al (2013) Chronic kidney disease: global dimension and perspectives. The Lancet 382(9888):260-272

11. Reddy MA, Natarajan R (2015) Recent developments in epigenetics of acute and chronic kidney diseases. Kidney Int 88(2):250-261

12. Luttropp K, Lindholm B, Carrero JJ et al (2009) Genetics/Genomics in chronic kidney disease-towards personalized medicine?Seminars in Dialysis 22(4):417-22

13. Quintero Ojeda JE, Aguilar-Medina M, Olimón-Andalón V et al (2018) Increased micronuclei frequency in oral and lingual epithelium of treated diabetes mellitus patients. BioMed Research International2018

14. Demircigil G, Aykanat B, Fidan K et al (2011) Micronucleus frequencies in peripheral blood lymphocytes of children with chronic kidney disease. Mutagenesis 26(5):643-650

15. Guido M, Zizza A, Tumolo MR et al (2016) Using the cytokinesis-block micronucleus cytome assay to evaluate chromosomal DNA damage in chronic renal patients undergoing bicarbonate haemodialysis and haemodiafiltration. J Prev Med Hyg 57(3):E178-E184

16. Cañadas-Garre M, Anderson K, McGoldrick J et al (2018) Genomic approaches in the search for molecular biomarkers in chronic kidney disease. Journal of Translational Medicine 16(1):292

17. Anderson K, Cañadas-Garre M, Chambers R et al (2019) The challenges of chromosome $Y$ analysis and the implications for chronic kidney disease. Front Genet 10:781

18. Sriramachari S (2004) The Bhopal gas tragedy: An environmental disaster. Curr Sci 86:905-920

19. National Cancer Registry Programme ICMR (2005) Two-year Report of the Population Based Cancer Registries (1999-2000)

20. Rooney DE, Czepulkowski BH (1992) Human Cytogenetics: A Practical Approach, vol 1, 2 edn. IRL Press at Oxford University Press, Oxford, New York

21. Fenech M (2000) The in vitro micronucleus technique. Mutat Res 455:81-95

22. Samarth RM, Gandhi P, Pandey H et al (2012) Mosaicism for trisomy 21 and ring (21) in a male born to normal parents: A case report. Gene 511:109-112

23. Samarth RM, Khan T, Srivas S et al (2018) Evaluation of cyclophosphamide-induced genotoxicity and cytotoxicity in cultured human lymphocytes. Journal of Radiation and Cancer Research 9:28-32

24. Schupp N, Heidland A, Stopper H (2010) Genomic damage in end stage renal disease-contribution of uremic toxins. Toxins 2(10):23402358

25. Ersson C, Thorman R, Rodhe $Y$ et al (2011) DNA damage in salivary gland tissue in patients with chronic kidney disease, measured by the comet assay. Oral Surgery, Oral Medicine, Oral Pathology, Oral Radiology and Endodontic112(2):209-215

26. Rangel-López A, Paniagua-Medina ME, Urbán-Reyes M et al (2013) Genetic damage in patients with chronic kidney disease, peritoneal dialysis and haemodialysis: a comparative study. Mutagenesis 28(2):219-225

27. Rodríguez Ribera L, Stoyanova E, Corredor Z et al (2014) Time in hemodialysis modulates the levels of genetic damage in hemodialysis patients. Environmental and Molecular Mutagenesis55(4):363-368

28. Locatelli F, Canaud B, Eckardt KU et al (2003) Oxidative stress in end-stage renal disease: an emerging threat to patient outcome. Nephrology Dialysis Transplantation 18(7):1272-1280

29. Schiffrin EL, Lipman ML, Mann JF (2007) Chronic kidney disease: effects on the cardiovascular system, vol 116. Circulation, pp 85-971

30. Dwivedi RS, Herman JG, McCaffrey TA et al (2011) Beyond genetics: epigenetic code in chronic kidney disease. Kidney Int 79(1):23-32

31. Del Vecchio L, Locatelli F, Carini M (2011) What we know about oxidative stress in patients with chronic kidney disease on dialysis-clinical effects, potential treatment, and prevention. Semin Dial 24(1):56-64

Page 6/7 
32. Sabharwal R, Verma P, Syed MA et al (2015) Emergence of micronuclei as a genomic biomarker. Indian Journal of Medical and Paediatric Oncology 36(4):212-218

33. Khan Z, Pandey M, Samartha RM (2016) Role of cytogenetic biomarkers in management of chronic kidney disease patients: A review. International Journal of Health Sciences 10(4):576-589

34. Palazzo RP, Bagatini PB, Schefer PB et al (2012) Genomic instability in patients with type 2 diabetes mellitus on hemodialysis. Revistabrasileira de Hematologia e Hemoterapia 34(1):31-35

35. Mamur S, Unal F, Altok K et al (2016) DNA damage in hemodialysis patients with chronic kidney disease; a test of the role of diabetes mellitus; a comet assay investigation. Mutation Research/Genetic Toxicology and Environmental Mutagenesis 800:22-27

36. Orr SE, Bridges CC (2017) Chronic kidney disease and exposure to nephrotoxic metals. Int J Mol Sci 18(5):1039

37. Ganguly BB, Mandal S, Banerjee N et al (2018) Effect of age at exposure on chromosome abnormalities in MIC-exposed Bhopal population detected 30years post-disaster. Mutat Res 809:32-50

38. Ipek E, Ermiş E, Uysal $\mathrm{H}$ et al (2017) The relationship of micronucleus frequency and nuclear division index with coronary artery disease SYNTAX and Gensini scores. Anatolian Journal of Cardiology 17(6):483-489

39. Chang CC, Chiu PF, Wu CL et al (2019) Urinary cell-free mitochondrial and nuclear deoxyribonucleic acid correlates with the prognosis of chronic kidney diseases. BMC Nephrol 20(1):391

40. Coimbra S, Rocha S, Nascimento H et al (2020) Cell-free DNA as a marker for the outcome of end-stage renal disease patients on haemodialysis. Clinical Kidney Journal sfaa115. https://doi.org/10.1093/ckj/sfaa115

41. Goswami HK, Guron C, Jain N et al (1984) Genetic assessment of Union Carbide gas tragedy in Bhopal. I. Effects on somatic chromosomes and haemoglobin. Bionature 4:88-90

42. Goswami HK (1986) Cytogenetic effects of methyl isocyanate exposure in Bhopal. Hum Genet 74:81-84

43. Goswami HK, Chandorkar M, Bhattacharya K et al (1990)Search for chromosomal variations among gas-exposed persons in Bhopal.Human Genetics84:172-176

44. Ghosh BB, Sengupta S, Roy A et al (1990) Cytogenetic studies in human populations exposed to gas leak at Bhopal, India. Environ Health Perspect 86:323-326

45. Malla TM, Sharma NC, Ganesh N (2010) Frequency of acrocentric associations in Bhopal gas tragedy survivors. International Journal of Cell and Molecular Biology 1:26-30

46. Malla TM, Senthilkumar CS, Sharma NC et al (2011) Chromosome instability among Bhopal gas tragedy survivors. American-Eurasian Journal of Toxicological Sciences 3:245-249

47. Senthilkumar CS, Malla TM, Sah NK et al (2013) Methyl isocyanate exposure and atypical lymphocytes. Int J Occup Environ Med 4(3):167168

48. Ganguly BB (2019) Exposure index of methyl isocyanate (MIC) gas disaster and a comprehensive spectrum of cytogenetic analysis after 30 years. Environ Sci Pollut Res Int 26(18):18208-18229

49. Ganguly BB, Mandal S, Kadam NN (2019) Frequency of micronuclei in population of Bhopal exposed to methyl isocyanate in 1984. The Nucleus 62:269-275 